\title{
Avaliação ergonômica do ambiente construído: estudo de caso da Universidade Integrada da Terceira Idade - UNITI/UFMA
}

\author{
Ergonomic evaluation of the built environment: case study of \\ Integrated Third Age University - UNITI/UFMA
}

\author{
ARTHUR JOSÉ SILVA MARQUES \\ Mestrando, UFMA, arthurgarre@gmail.com \\ RAILDE PAULA DINIZ ARAÚJO \\ Mestra, UFMA, raildediniz@gmail.com \\ LÍVIA FLÁVIA DE ALBUQUERQUE CAMPOS \\ Doutora, UFMA, liviaflavia@gmail.com
}

\section{RESUMO}

O aumento da população idosa é uma constante em todo o mundo. No Brasil estes números têm crescido significativamente de acordo com os dados estatísticos do IBGE (2010) e da Sociedade Brasileira de Geriatria e Gerontologia (2014). Contudo, o envelhecimento não deve ser entendido como a etapa final da vida humana, mas um momento de ressignificação da idade. Por isso, é necessário criar estratégias para melhorar as condições físicas, psicológicas e sociais da população que envelhece. Pensando nisso, o ambiente educacional proposto pelas Universidades para a Terceira Idade, mostrase importante. O presente artigo tem como objetivo a avaliação do ambiente de ensino da Universidade Integrada da Terceira Idade - UNITI/UFMA, pelos princípios propostos na Metodologia Ergonômica do Ambiente Construído - MEAC, onde foram realizadas as etapas metodológicas: Análise global do ambiente; Identificação da configuração ambiental; Avaliação do ambiente em uso; Percepção ambiental do usuário, onde foi utilizado a ferramenta "estrela de valor" de Krucken (2009) e finalizando com a etapa de Diagnose e as recomendações, onde levantou-se alguns apontamentos a serem discutidos e averiguados com relação a constrangimentos e adequações as normas da ISO e NBR's destinadas ao ambiente de ensino.

PALAVRAS-CHAVE: terceira idade, ergonomia, educação, ambiente de ensino

\section{ABSTRACT}

The increase in the elderly population is a constant worldwide. In Brazil these numbers have grown significantly according to statistical data from IBGE (2010) and the Brazilian Society of Geriatrics and 


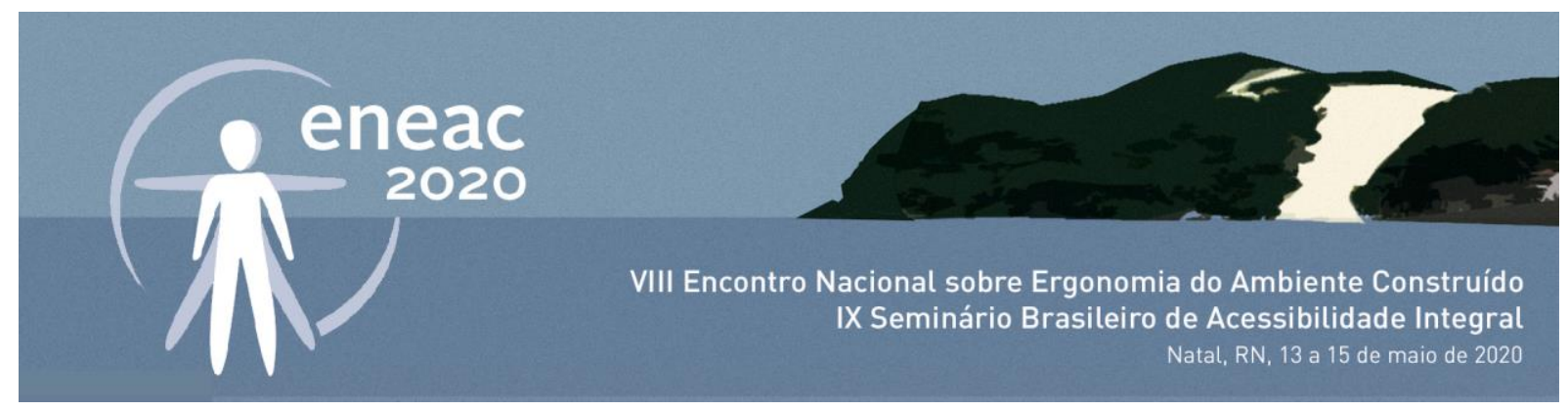

Gerontology (2014). However, aging should not be understood as the final stage of human life, but a moment of redefinition of age. Therefore, it is necessary to create strategies to improve the physical, psychological and social conditions of the aging population. Thinking about it, the educational environment proposed by Universities for the Elderly, proves to be important. This article aims to evaluate the teaching environment of the Integrated University of the Third Age - UNITI / UFMA, by the principles proposed in the Ergonomic Methodology of the Built Environment - MEAC, where the methodological steps were carried out: Global analysis of the environment; Identification of the environmental configuration; Assessment of the environment in use; Environmental perception of the user, where Krucken's "value star" tool (2009) was used and ending with the Diagnosis stage and the recommendations, which raised some notes to be discussed and investigated regarding constraints and adjustments to ISO standards and NBR's for the teaching environment.

KEYWORDS: elderly, ergonomics, education, teaching environment

\section{INTRODUÇÃO}

O envelhecimento populacional é uma constante em todo o mundo. De acordo com Carvalho e Garcia (2003), esse processo iniciou-se no final do século XX em alguns países da Europa Ocidental, espalhou-se pelo resto do primeiro mundo, no século passado, e se estendeu nas últimas décadas, por vários países do terceiro mundo.

Segundo dados da Organização das Nações Unidas - ONU (2003), no século XX teve-se uma revolução na longevidade. A expectativa média de vida ao nascer aumentou 20 anos desde 1950 e, previsões indicam que até 2050 terá aumentado mais 10 anos. Essa mudança demográfica e o acelerado crescimento da população na primeira metade do século XXI, significam que o número de pessoas com mais de 60 anos, que era de aproximadamente de 600 milhões, no ano de 2000, chegue a quase dois bilhões em 2050 (ONU, 2003). Para Silva (2003), esse crescimento se deu em consequência da industrialização, da urbanização, dos avanços da medicina e tecnologia, e do saneamento básico.

Contudo, essas mudanças demográficas serão mais notadas nos países em desenvolvimento, onde há projeções de que a população idosa quadruplique nos próximos 50 anos, com isso, proporcionando uma inversão da pirâmide etária. Segundo Valente (2011), na América Latina o processo de envelhecimento populacional é mais acelerado do que na Europa. Em 2000, a população com mais de 60 anos era de 43 milhões, em 2025 estará em torno de 100,5 milhões e em 2050 chegará aos 183,7 milhões.

De acordo com a Sociedade Brasileira de Geriatria e Gerontologia - SBGG (2014), o envelhecimento no Brasil, iniciou-se a partir de 1960 e as mudanças se dão a largos passos. Em 1940, a população brasileira era composta por $42 \%$ de jovens com menos de 15 anos, enquanto os idosos representavam apenas 2,5\%. No último Censo do Instituto Brasileiro de Geografia e Estatística - IBGE, em 2010, a população de jovens foi reduzida para $24 \%$ do total. Por sua vez, os idosos passaram a representar $10,8 \%$ do povo brasileiro, ou seja, mais de 20,5 milhões de pessoas possuem 60 anos, isto representa um incremento de $400 \%$ se comparado ao índice anterior (IBGE, 2010).

Sendo assim, se mantidas as tendências observadas no último censo do IBGE, o Brasil caminha em direção a um perfil demográfico cada vez mais envelhecido, implicando assim, na necessidade de 


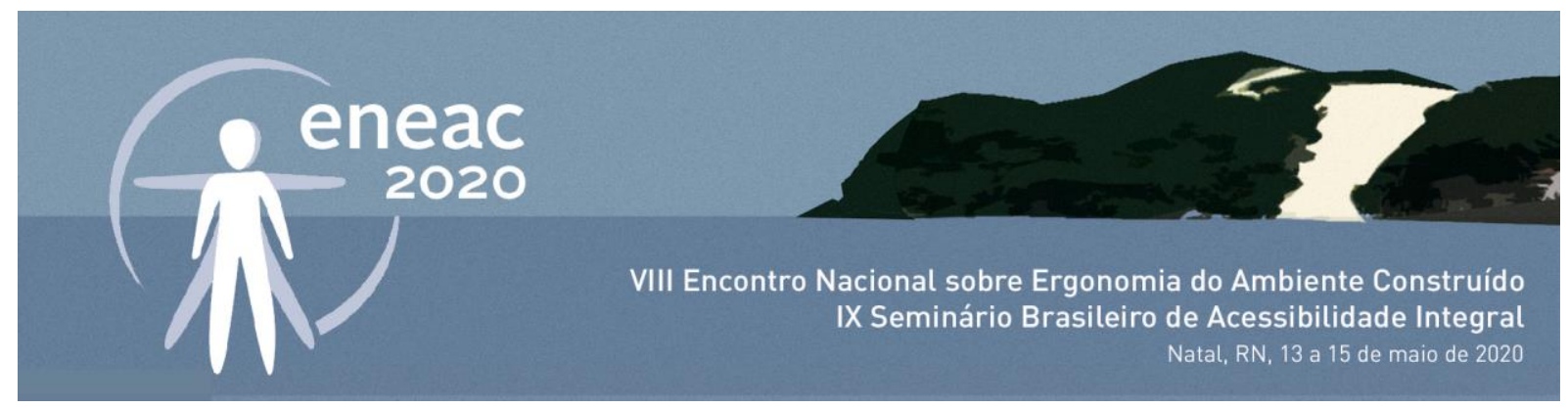

políticas públicas, particularmente aquelas voltadas para a saúde, previdência e assistência social para a população que envelhece. Com isso, pensar o ambiente educacional no âmbito das Universidades para a Terceira Idade, mostra-se necessário, uma vez que este local, para os idosos, possibilita o pertencimento social e a ressignificação da velhice.

Assim, o presente artigo apresenta o contexto da educação na terceira idade, desde sua origem na França à criação das instituições destinadas ao ensino da população envelhecente do Brasil. Discorre ainda, sobre as normas que regulamentam os ambientes destinados ao ensino. Por fim, a avaliação do ambiente de ensino da Universidade Integrada da Terceira Idade - UNITI/UFMA, pelos princípios propostos na Metodologia Ergonômica do Ambiente Construído - MEAC, auxiliado pela "estrela de valor", ferramenta usada por Krucken (2009) para traduzir dados qualitativos em representações gráficas. Desta Maneira, identificou-se os problemas existes relacionados as dimensões do ambiente, mobiliário, conforto térmico, lumínico e acústico, e demais fatores condicionantes, e relacionando-os com a percepção dos discentes sobre o ambiente de ensino da instituição.

\section{ENSINO DA TERCEIRA IDADE}

A primeira instituição a oferecer um curso totalmente para os idosos foi a Université du Troisième Age - U3A, fundada em 1973 por Pierre Vellas na cidade de Toulouse, na França, a partir de sua experiência de vida com as pessoas idosas e com o objetivo de retardar o processo de envelhecimento através do exercício físico e mental (NATALI, 2006).

A partir dessa iniciativa local, o movimento U3A se espalhou por todo o mundo de tal modo que, hoje, milhões de pessoas idosas de diversos países, de diferentes continentes, participam de uma série de atividades intelectuais e culturais que contribuem para o envelhecimento ativo e, consequentemente, uma velhice bem-sucedida (CACHIONI; ORDONEZ, 2013, pg. 152).

No Brasil, a primeira instituição voltada para o ensino de pessoas adultas e idosas, surgiu na década de 80, criada pelo Serviço Social do Comércio - SESC, baseada nos princípios geriátricos da instituição francesa. A princípio essa instituição se constituía como espaço para a convivência e lazer, como uma preparação para a aposentadoria. Entretanto, o molde desta instituição se mostrou de grande êxito, fazendo que houvesse melhorias em seu currículo e a propagação dos primeiros movimentos para idosos e das primeiras Escolas Abertas à Terceira Idade. Com isso, as instituições de ensino superior brasileiras demonstraram interesse nestes programas voltados a esta parcela da população, contribuindo assim para a disseminação desses ambientes educacionais.

As Universidades para a Terceira Idade são espaços voltados para a socialização da pessoa idosa, com o objetivo de valorizar e quebrar o seu estigma como pessoa incapaz. Segundo Silva et al (2017), constata-se que, das 63 universidades públicas federais brasileiras, 36 têm ações à educação permanentes aos idosos.

Seguindo os mesmos passos das instituições de ensino superior do Brasil, as Universidades Federal e Estadual do Maranhão, em parceria com o Serviço Social do Comércio do Maranhão - SESC/MA, a Secretaria de Planejamento, Orçamento e Gestão do Maranhão, inauguram em São Luís, em 1995, a Universidade Integrada da Terceira Idade - UNITI. Sendo este um espaço de convivência e ressocialização social, onde os discentes dispõem de aulas práticas, teóricas e de todos os benefícios 


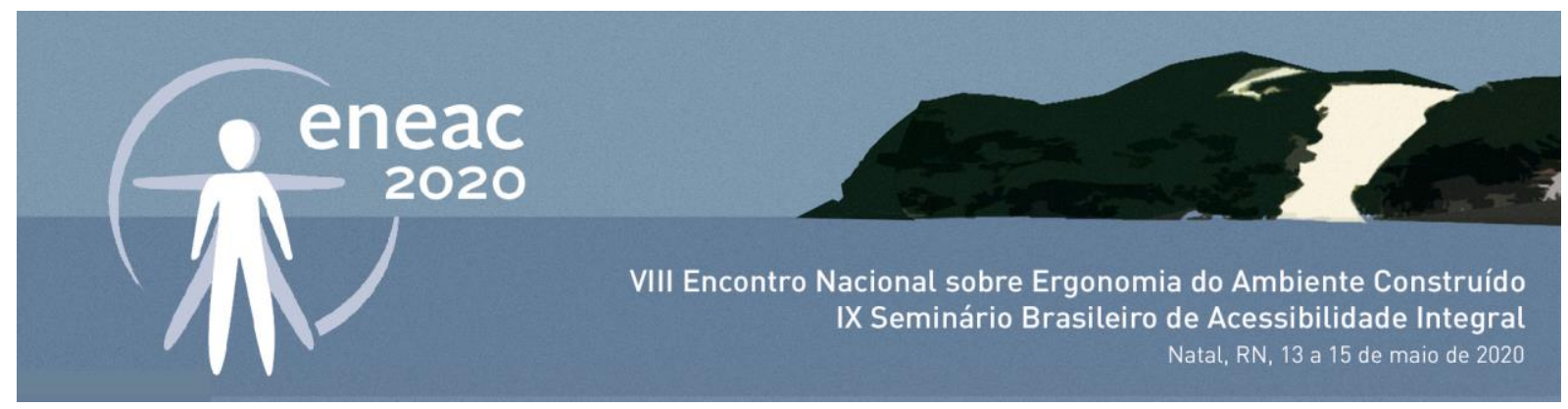

disponibilizados pelas instituições. Podendo assim, assumir um processo de envelhecimento saudável e consciente e gozar do exercício pleno de sua cidadania.

Por isso, considerando os benefícios que estes ambientes de ensino trazem aos idosos, torna-se importante que o ambiente educacional seja planejado para que contemple plenamente estes indivíduos, cuja bagagem de vida e de experiência ainda possui ampla capacidade de crescimento.

\section{NORMAS PARA O AMBIENTE DE ENSINO}

De acordo Ornstein (1996), todos os edifícios destinados à educação devem estar sujeitos a obediência de normas e padrões básicos de projeto e construção, capazes de garantir uma oferta adequada de espaço para o processo pedagógico. Barros et al (2015) dizem que "sob o ponto de vista dos aspectos legislativos direcionados a configuração de ambientes, uma série de recomendações é preconizada por institutos de normas técnicas e difundida por todo o país".

No Brasil, a Associação Brasileira de Normas Técnicas - ABNT, é o órgão responsável pela elaboração e disseminação do conjunto de normas técnicas que regulamentam processos e procedimentos nos mais variados âmbitos, desde pesquisas acadêmicas a processos industriais. Quando se trata do ambiente de ensino, estas normas não devem ser ignoradas, uma vez que, como afirma Moura et al (2018), "o ambiente desempenha um papel fundamental na formação do aluno e para que a aprendizagem seja efetiva e que haja desenvolvimento intelectual, ele deve ter contato com um espaço físico estimulante e criativo".

Sendo assim, as Normas Brasileiras Regulamentadoras - NBR, fundamentam os critérios que são utilizados como parâmetros necessários para proporcionar ambientes educacionais adequados aos seus usuários. Sendo a Norma Regulamentadora no 17 (NR-17) a responsável por estabelecer os princípios ergonômicos destes ambientes, pois aborda questões como iluminação, mobiliário, conforto térmico e acústico, revestimentos, ventilação e outras questões que possam interferir na realização da tarefa. Além desta, há a International Organization for Standardization (ISO) que também determina normas que regem processos produtivos, documentos e afins. Figueiredo e Paoliello (2001), afirmam que:

\footnotetext{
Buscar o entendimento do ambiente escolar sob a ótica da ergonomia é analisar o sujeito envolvido desde sua capacidade, no qual envolvem fatores que podem interferir na concentração do sujeito, até elementos como mobiliário inadequado e desconfortável, salas com iluminação e ventilação pouco eficientes e vários outros fatores (FIGUEIREDO E PAOLIELLO, 2001, pg.32.)
}

Villarouca e Andreto (2008), corroboram dizendo que "quando um ambiente físico responde às necessidades dos usuários tanto em termos funcionais (físico/cognitivos) quanto formais (psicológicos), certamente terá um impacto positivo na realização das atividades". Por isso, torna-se fundamental analisar o ambiente de ensino da terceira idade sob a ótica da ergonomia, pois trata-se de um local que atende uma parcela da população que é acometida por características do processo de envelhecimento e precisa de ambientes que fomentem suas potencialidades. 


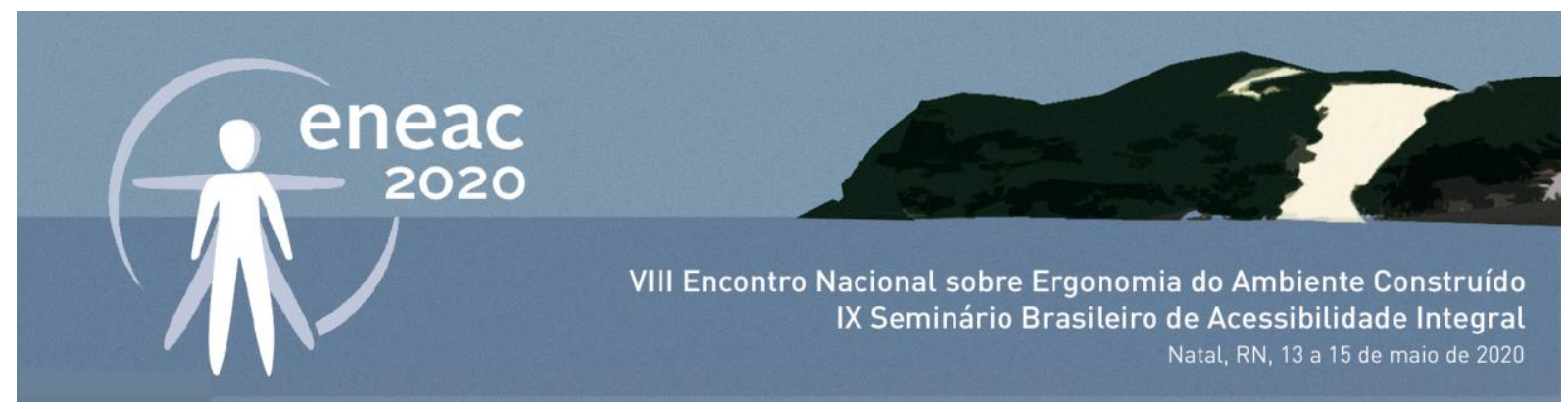

\section{METODOLOGIA}

A presente pesquisa teve como objetivo analisar o ambiente de ensino da Universidade Integrada da Terceira Idade - UNITI/UFMA, sob o olhar da Metodologia Ergonômica para o Ambiente Construído MEAC, proposto por Villarouco (2009). Através desta, busca-se entender, avaliar e propor melhorias no ambiente, para que este atenda aos requisitos propostos pelas NBR's e esteja adequado aos seus usuários.

A MEAC está dividida em cinco etapas gerais, sendo as três primeiras etapas relacionadas as avaliações físicas do ambiente, a quarta avalia a percepção do usuário sobre o espaço utilizado, e a quinta e última etapa, têm-se a diagnose e as recomendações. Para o presente trabalho realizou-se as etapas da MEAC, apenas no ambiente físico do prédio do CEB Velho, onde os discentes têm a maioria das aulas, com isso, passando mais tempo neste local.

\section{1a Etapa: Análise Global do Ambiente}

Universidade Integrada da Terceira Idade - UNITI/UFMA, foi fundada em 1995, e está localizada na Cidade Universitária Dom Delgado na cidade de São Luís, Maranhão. As aulas da instituição são distribuídas em quatro prédios do campus e os alunos divididos em três turmas ( $A, B$ e $C$ ). $A$ aula de Fitoterapia acontece no Prédio do Herbário, localizado no Centro de Ciências Biológicas e da Saúde CCBS. A aula de Informática acontece no Prédio de Ciências Exatas e Tecnologia - CCET. As aulas de Ritmos e Danças, Yoga, e Hidroginástica acontecem no Núcleo de Esportes, prédio que é o ponto final da linha de ônibus que dá acesso à cidade universitária. As aulas teóricas de Lazer e Turismo, Noções Básicas de Gerontologia, Reeducação Alimentar/Nutrição, Aeróbica Mental, Concentração e Memória, Línguas (Inglês, Espanhol e Francês), Psicologia na Terceira Idade, Musicalização, funcionam no Prédio do CEB Velho (prédio da biblioteca central) da UFMA, onde dispõem de uma sala para a coordenação, uma sala de atendimento psicológico, um banheiro e três salas de aula, sendo este o prédio onde os discentes da instituição passam a maior parte do tempo.

As atividades da UNITI são distribuídas nos turnos matutino (09:00h às 12:00h) e vespertino (14h:00 às 17:00h), de segunda a sexta-feira. As aulas dos prédios CCBS, CCET e Núcleo de Esportes, são dadas pelo horário da manhã e as demais aulas no turno da tarde. No hall (imagem 01) do prédio da UNITI (CEB Velho) há um bebedouro e quatro bancos de concreto, local onde os discentes passam o tempo entre os turnos de aula. Todas as salas de aula ( $A, B$ e $C$ ) possuem portas com grades, dois ares-condicionados, lousa branca, lixeiro e datashow. Além das cadeiras e mesa para o professor. 


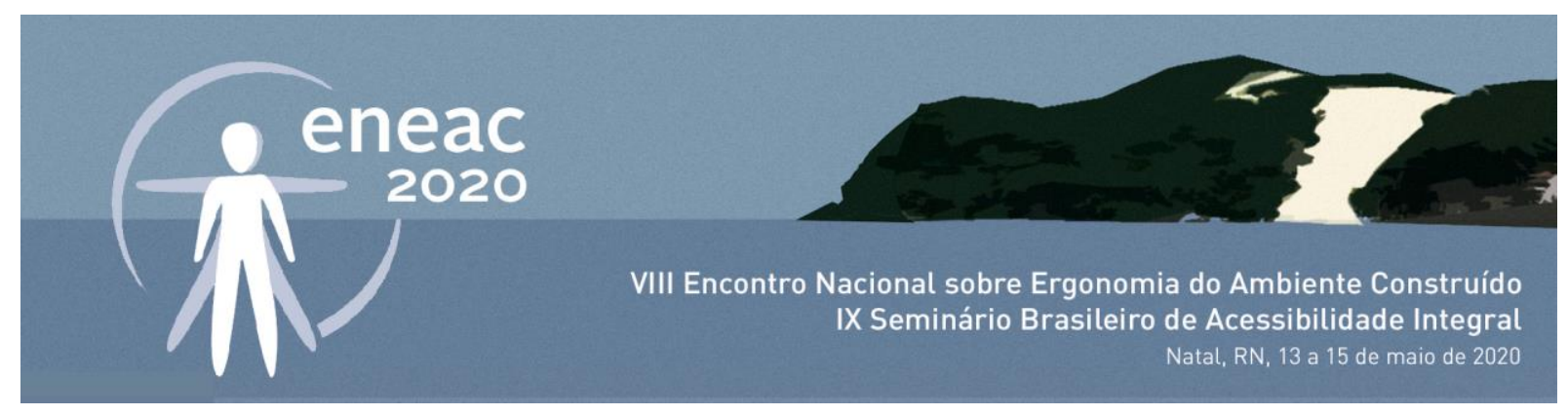

Imagem 01: hall da UNITI, prédio do CEB Velho.

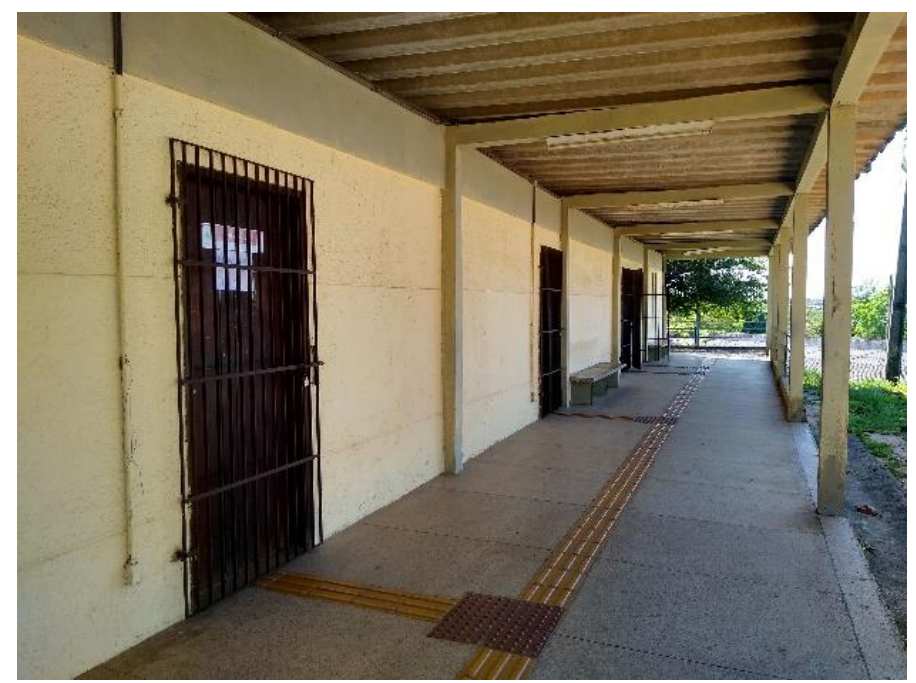

Fonte: Autores, 2019.

\section{2a Etapa: Identificação da Configuração Ambiental}

A UNITI localiza-se na parte posterior do prédio CEB Velho, possuindo um banheiro e cinco salas, sendo três delas destinadas as aulas. No hall há quatro bancos de concreto, sendo três maiores de dimensões $45 \times 270 \times 40 \mathrm{~cm}$, e um menor de dimensão $45 \times 160 \times 43 \mathrm{~cm}$; um lixeiro de fibra de vidro; um bebedouro industrial (PRE 2000 Acqua Gelata) em aço inox, com duas torneiras e duas válvulas jato, porém não refrigera a água; piso industrial granilite e piso tátil (imagem 02).

Imagem 02: hall da UNITI.

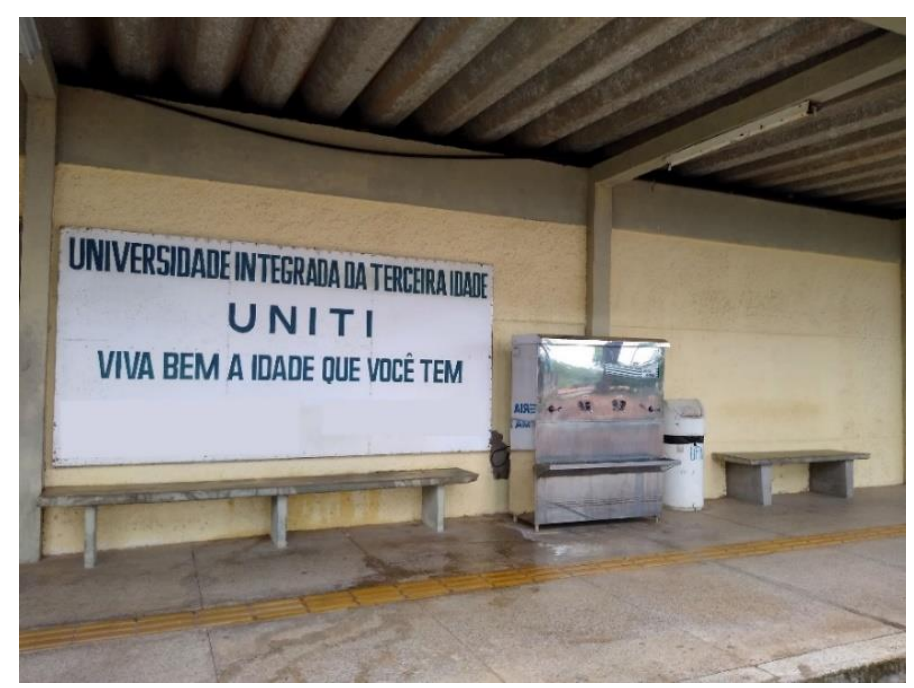

Fonte: autores, 2019. 


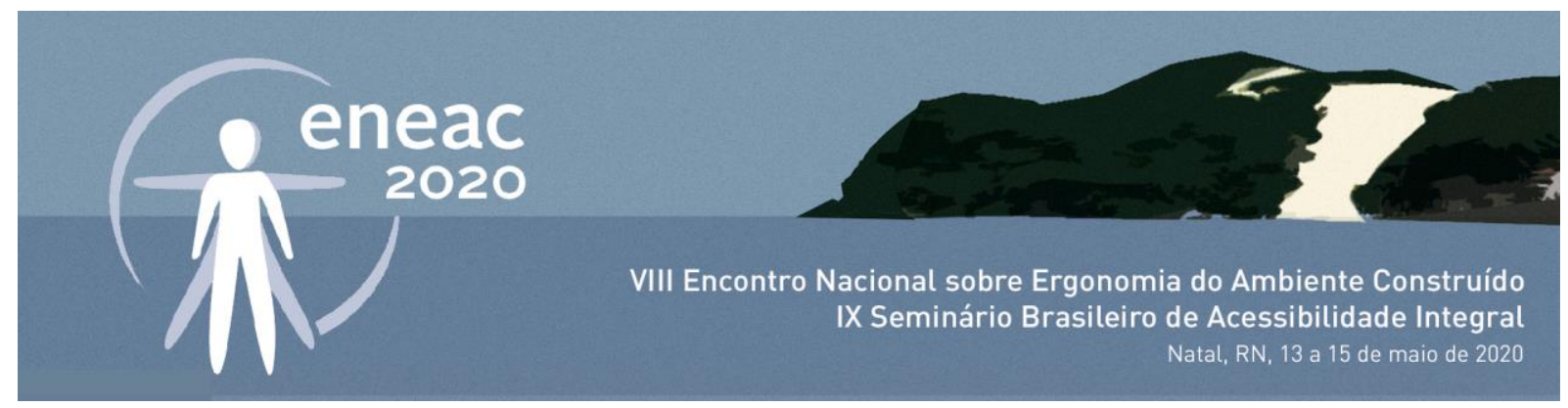

A sala A possui dois ares-condicionados (LG Split 1800 BTUS; LG TS-H092 JBAO Split 9000 BTUS), quatro pontos de luz com luminárias sobrepor tubular com duas lâmpadas fluorescentes cada, totalizando oito lâmpadas no ambiente, porém um ponto não está funcionando; duas tomadas de três pinos, com a tubulação externa a parede; uma lousa branca em fórmica (imagem 03); um datashow (Epson 2700 Lumens), que fica fixo no teto; uma lona para receber a projeção, que fica a cima da lousa; uma mesa e uma cadeira para o professor; e um armário de metal que guarda material da coordenação. A sala dispõe de mais de cinquenta cadeiras, sendo vinte delas com assento e encosto em polipropileno injetado, com acabamento em tecido, prancha em Placa de Fibra de Média Densidade (MDF) revestida em laminado melamínico, tubo de aço carbono e pintura eletrostática a pó; e as demais são de madeira compensada com assento, encosto e prancha revestidos em fórmica bege, tubo de aço e pintura eletrostática epóxi preta.

Imagem 03: sala A da UNITI.

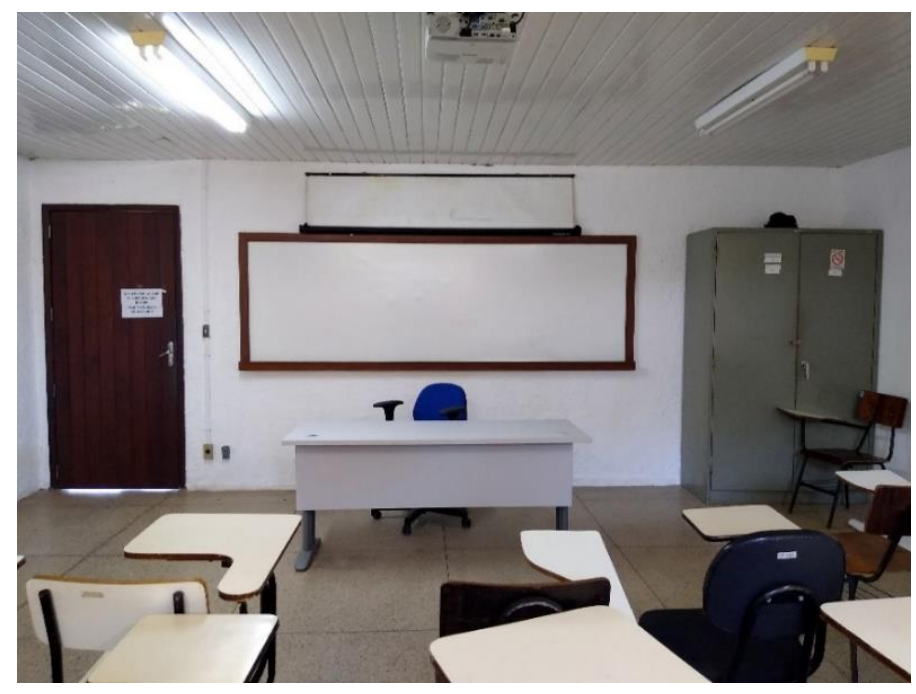

Fonte: autores, 2019.

A sala B possui dois ares-condicionados (LG Split 1800 BTUS; LG TS-H092 JBAO Split 9000 BTUS), quatro pontos de luz com luminárias sobrepor tubular com duas lâmpadas fluorescentes cada, somando oito lâmpadas no ambiente; duas tomadas de três pinos, com a tubulação externa a parede; uma lousa branca em fórmica; um datashow (Epson 2700 Lumens), que fica fixo no teto; um tripé móvel com lona para receber a projeção (imagem 04); uma lona para receber projeção fica ao lado da lousa, porém, esta não é utilizada. Duas mesas e uma cadeira para o professor. A sala dispõe de mais de cinquenta cadeiras, sendo seis delas com assento e encosto em polipropileno injetado, com acabamento em tecido, prancha em Placa de Fibra de Média Densidade (MDF) revestida em laminado melamínico, tubo de aço carbono e pintura eletrostática a pó; e as demais são de madeira compensada com assento, encosto e prancha revestidos de fórmica bege, tubo de aço e pintura eletrostática epóxi preta. 


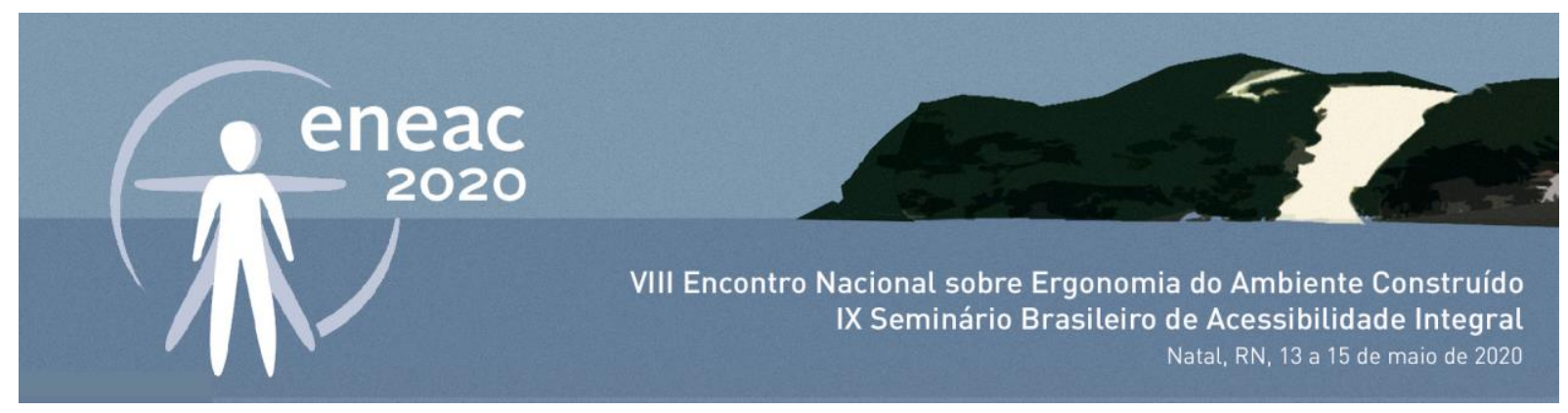

Imagem 04: sala B da UNITI.

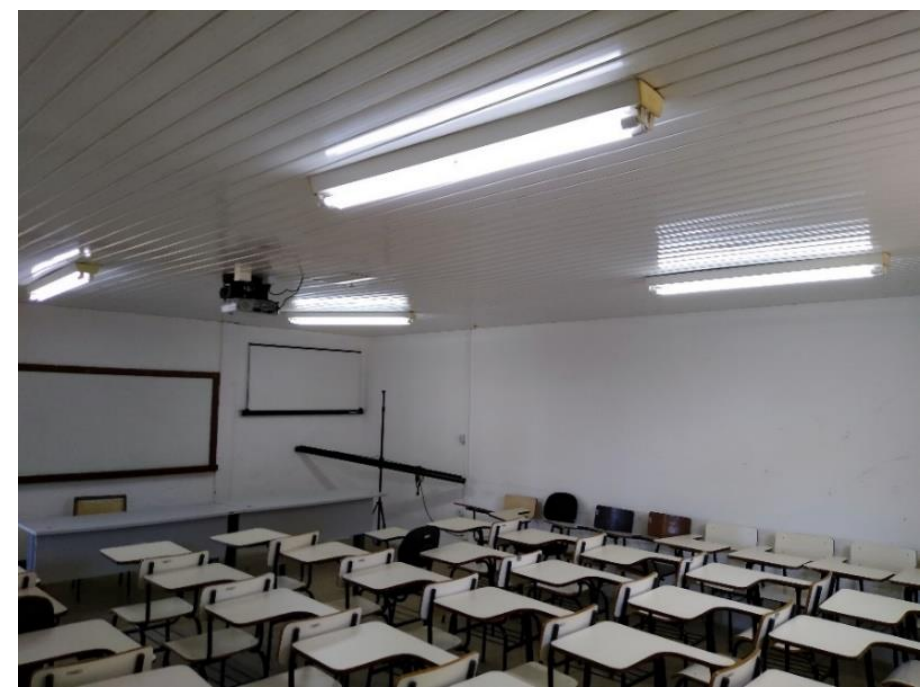

Fonte: autores, 2019.

A sala C possui dois ares-condicionados (Elbus Split 1200 BTUS; LG TS-H092 JBAO Split 9000 BTUS), quatro pontos de luz com luminárias sobrepor tubular com duas lâmpadas fluorescentes cada, totalizando oito lâmpadas no ambiente (imagem 05); duas tomadas de três pinos, com a tubulação externa a parede; uma lousa branca em fórmica; um datashow (Epson 2700 Lumens), que fica fixo no teto; uma lona para receber a projeção, que fica acima da lousa; uma mesa e uma cadeira para o professor. A sala dispõe de mais de cinquenta cadeiras, porém, apenas dez delas com assento e encosto em polipropileno injetado, com acabamento em tecido, prancha em Placa de Fibra de Média Densidade (MDF) revestida em laminado melamínico, tubo de aço carbono e pintura eletrostática a pó; e as demais são de madeira compensada com assento, encosto e prancha revestidos de fórmica bege, tubo de aço e pintura eletrostática epóxi preta.

Imagem 05: sala C da UNITI.

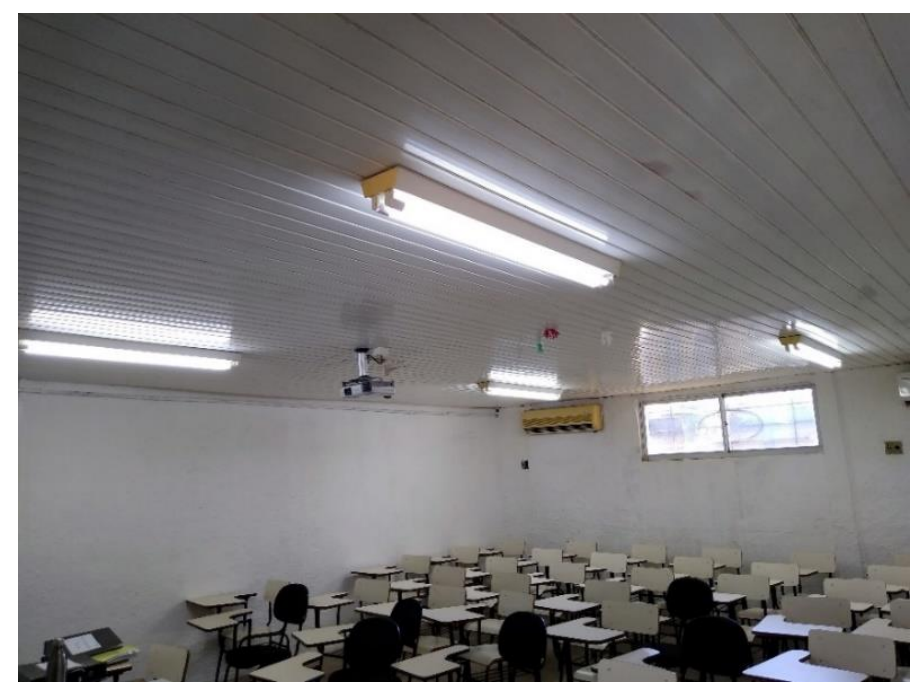

Fonte: autores, 2019. 


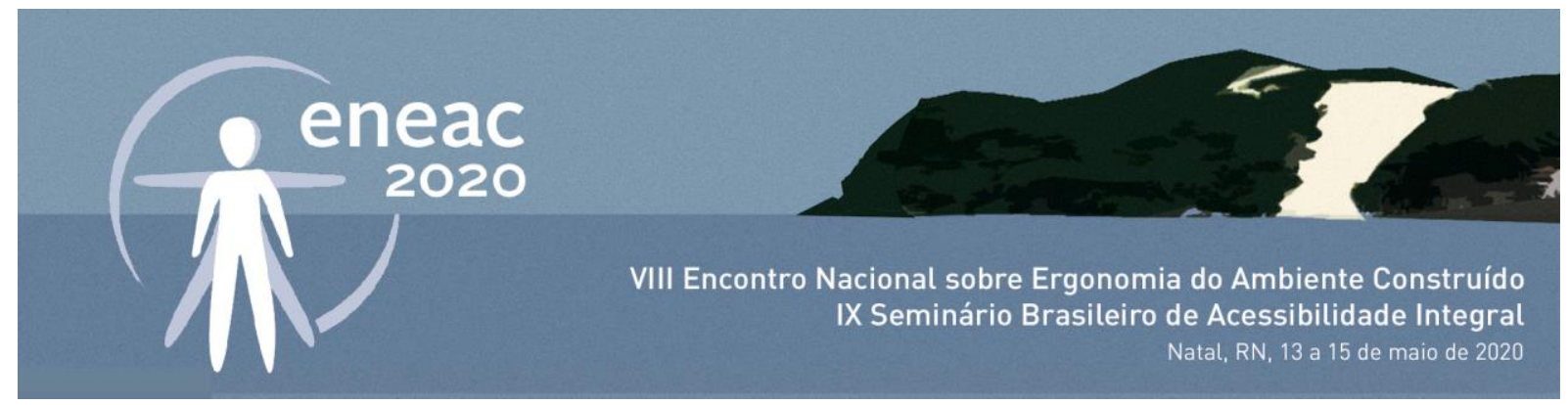

As três salas possuem dimensão de $545 \times 746 \mathrm{~cm}$; piso industrial granilite; portas de madeira nas dimensões de $90 \times 210 \mathrm{~cm}$, com grade de ferro $110 \times 220 \mathrm{~cm}$; paredes brancas texturizadas; forro de Cloreto de Polivinila (PVC) branco; possuem uma janela de vidro com dimensões $70 \times 190 \mathrm{~cm}$ de duas folhas, esta fica localizada na parede ao fundo da sala (imagem 06); uma lousa em fórmica nas dimensões 267 x $103 \mathrm{~cm}$ e um lixeiro telado de plástico (polímero).

Imagem 06: parede que possui a janela e os ares-condicionados.

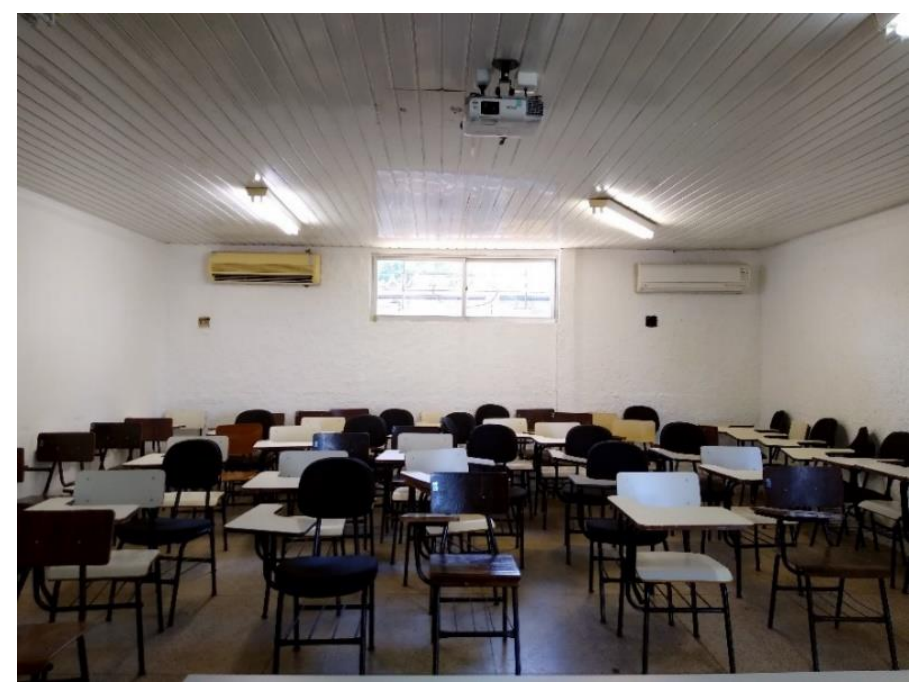

Fonte: autores, 2019.

\section{3a Etapa: Avaliação do Ambiente em Uso}

Nesta etapa, foi possível acompanhar as aulas da UNITI e fazer observações. Segundo Marconi e Lakatos (2016) a "observação é uma técnica de coleta de dados para conseguir informações e utiliza os sentidos na obtenção de determinados aspectos da realidade. Não consiste apenas em ver e ouvir, mas também em examinar fatos ou fenômenos que se deseja estudar". Pôde-se perceber que há interrupção da concentração nas aulas, uma vez que a porta fica ao lado da lousa e sempre que alguém chega, desperta a atenção dos alunos; alguns dos ares-condicionados fazem ruído; há reclamações dos discentes de não enxergarem o que está sendo escrito na lousa por causa de excesso e/ou falta de luz; reclamações de calor e/ou frio; há dificuldade de circulação nas salas, uma vez que há cadeiras a mais no ambiente; quando o datashow é utilizado, apagam-se as luzes, porém a janela que fica no fundo da sala é translúcida, e esta fica na direção da lona que recebe a projeção, com isso, a entrada de luz no ambiente dificulta a visualização do que está sendo projetado. Por tanto, as observações do ambiente de ensino proporcionam aos pesquisadores os critérios/requisitos para que estes possam averiguar e confrontar com as falas dos usuários na etapa posterior. 


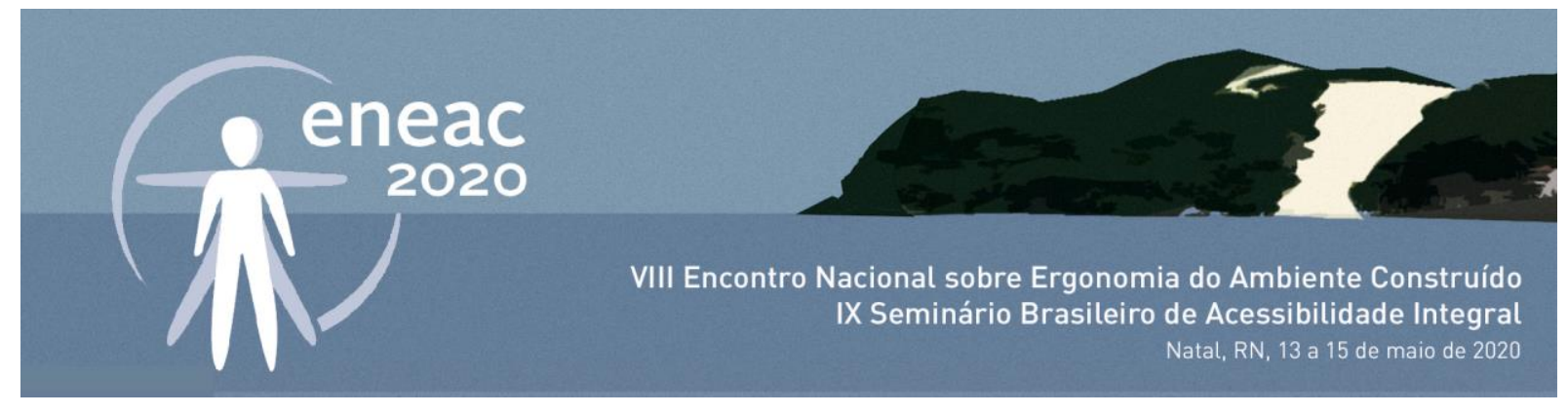

\section{4a Etapa: Percepção Ambiental do Usuário}

Segundo Villarouco (2008), um ponto importante da avaliação do ambiente construído é a percepção do usuário, pois este é o elemento que mais sofre com todas sensação que o ambiente pode gerar. Assim, para a coleta de dados com os discentes, foram realizadas entrevistas. Para as posteriores transcrições e análises dos dados, estas foram gravadas com a autorização dos pesquisados através do Termo de Consentimento Livre e Esclarecido - TCLE e respaldado pelo projeto aprovado pelo Comitê de Ética da Universidade Federal do Maranhão - UFMA, sob o número: 3.213.189. A amostra contou com 20 alunos com média de Idade 67 anos. As entrevistas aconteceram nos turnos matutino e vespertino nos meses de novembro e dezembro de 2019, nos prédios do CEB Velho, o critério de seleção da amostra foi a disponibilidade dos voluntários.

Foi utilizado um questionário fechado, este estava dividido em duas partes, a primeira com perguntas sobre o projeto UNITI e a importância deste para o discente; e a segunda parte com questões relacionadas a problemas ambientais/estruturais. Com a transcrição dos dados foi possível elencar as informações sobre o olhar dos discentes sobre a instituição. Além, de identificar os constrangimentos que estes sofrem com as inadequações estruturais do ambiente.

Com isso, para a análise dos dados foi utilizado a "estrela de valor", ferramenta utilizada por Krucken (2009), que consiste em seis dimensões de valores a qual são atribuídas características que permitem posicionar e determinar o grau de importância de cada elemento avaliado, com isso, é possível representar graficamente questões subjetivas. De acordo a autora as seis dimensões são:

- Valor funcional ou utilitário - mensurado por atributos objetivos, caracteriza-se pela "adequação ao uso". Refere-se às qualidades intrínsecas do produto, sua composição, origem e propriedades, à segurança de consumo e a aspectos ergonômicos;

- Valor emocional - de caráter subjetivo, incorpora motivações afetivas relacionadas às percepções sensoriais que compreendem componentes táteis, visíveis, olfativos e gustativos. Incorpora, ainda, a nossa dimensão "memorial", relativa a lembranças positivas e negativas de acontecimentos passados;

- Valor ambiental - vinculado principalmente à prestação de serviços ambientais por meio do uso sustentável dos recursos naturais como as florestas;

- Valor simbólico e cultural - profundamente relacionado às outras dimensões da qualidade, do sentido de pertença que evoca. Está associado ao desejo de manifestar a identidade social, pertença em grupo étnico, posicionamento político, dentre outras intenções. Fortemente influenciado pelo contexto sociocultural (época, local) e pelos fenômenos contemporâneos;

- Valor social - Os valores morais dos cidadãos e a atuação e a reputação das organizações na sociedade;

- Valor econômico - de caráter objetivo, baseia-se na relação custo/benefício em termos monetários.

Com estas dimensões definidas, pode-se analisar resultados qualitativos da pesquisa e posiciona-los na "estrela de valor", construindo uma malha que possibilita perceber visualmente a percepção dos pesquisados sobre a UNITI. 


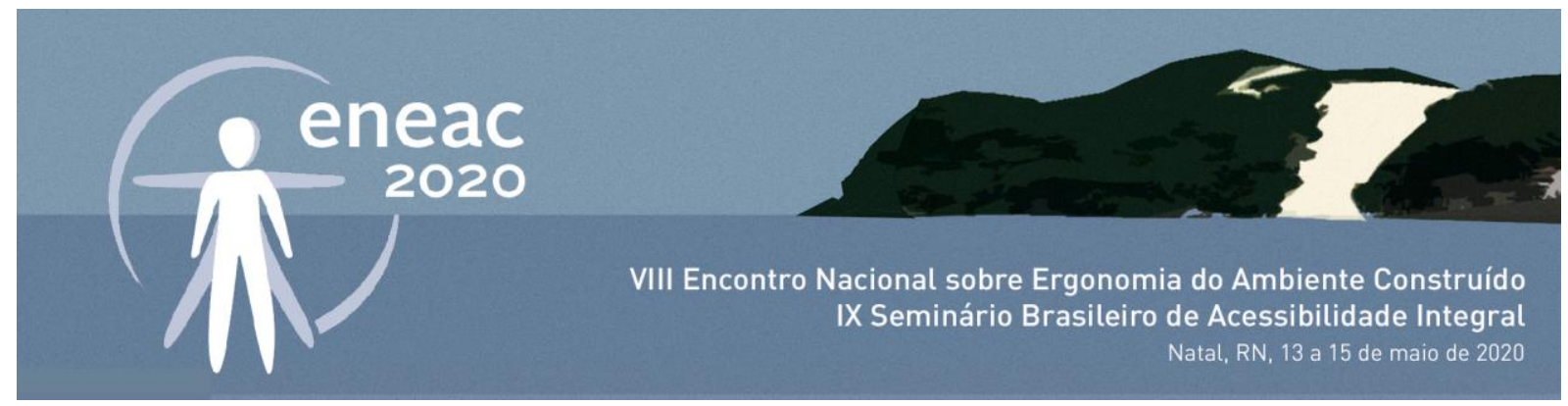

Imagem 07: "estrela de valor".

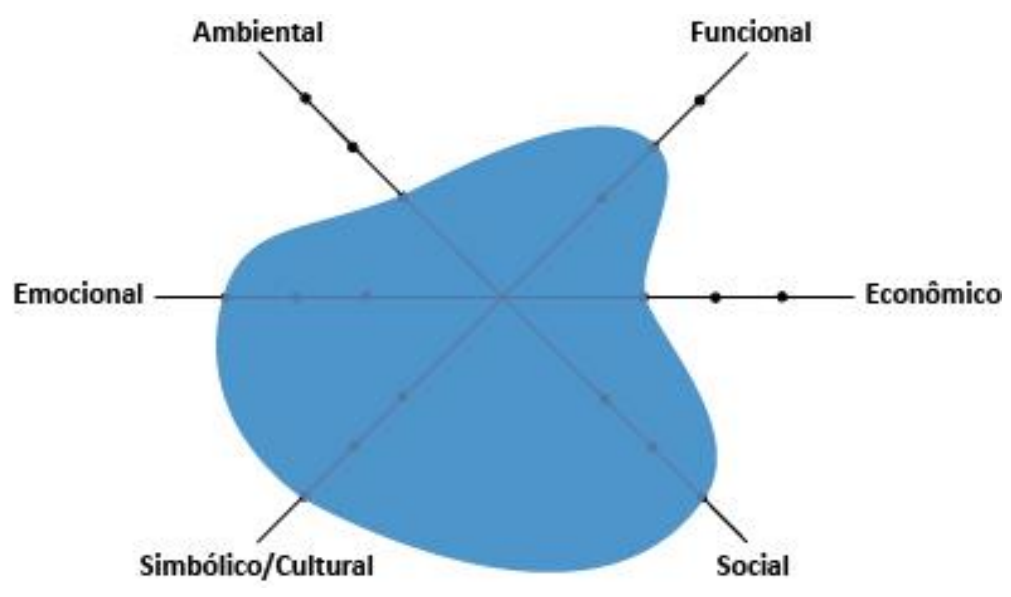

Fonte: elaborado pelos autores (2019) com base em Krucken (2009).

Por meio da "estrela de valor", foi possível reconhecer na fala de todos os usuários que os aspectos mais relevantes para os mesmos são os valores emocional, simbólico/cultural e social, pois são aqueles que contemplam a representação da relação destes com à UNITI, visto que, é o local onde sentem-se pertencentes, como é possível perceber nas suas falas.

\footnotetext{
"Muito bom, é ótimo, é ótimo esse projeto é ótimo, eu costumo dizer que isso aqui não é só uma terapia, isso aqui é um hospital, que a gente chega aqui arrasado, a gente assiste essas aulas a autoestima sobe, a gente se sente bem, feliz, e a gente quer compartilhar com todas as pessoas a felicidade que a gente tá tendo aqui" (USUÁRIO, 2019).
}

O valor funcional, que aborda as questões ergonômicas, mostrou-se bastante presente nas respostas, porém estes problemas ficam em segundo plano pelos usuários, mas tem peso significativo, como demonstram em algumas respostas.

"Na sala de aula eu só acho o espaço muito pequeno, né. Muitas pessoas dentro da sala, as cadeiras se encostando uma na outra porque a gente não tem espaço, pra gente ficar mais assim, mais espaçosos. Era melhor se aumentasse mais a sala também, né. lluminação e ar condicionado não tive problema não" (USUÁRIO, 2019).

Percebe-se que mesmo aqueles, doze usuários, que dizem que o ambiente físico não está bom ou poderia melhorar, são gratos pela acolhida e inclusão na UNITI e sempre justificam os pontos negativos dizendo que é o que a instituição pode oferecer e que o mais importante é não deixar as pessoas que querem participar de fora. Assim, os desconfortos e os problemas estruturais são relevados pelos discentes. 




\section{5a Etapa: Diagnose e Recomendações}

A partir das etapas realizadas, constatou-se que diversas são as demandas encontradas no ambiente de ensino da UNITI. Quanto as classes dos problemas foram categorizados em: movimentacionais, estruturais/arquitetura de interiores, físico-ambientais.

Os problemas movimentacionais estão relacionados ao grande contingente de cadeiras (mais de 50) em um espaço $(545 \times 746 \mathrm{~cm}$ ) que não comporta esta quantidade, fazendo que os discentes não tenham espaço suficiente para se locomover livremente pela sala de aula. Portanto, sugere-se reduzir a quantidade de cadeiras, deixando apenas a quantidade que assiste o número de alunos.

Os de caráter estruturais/arquitetura de interiores, relacionam-se com o layout e mobiliário. É importante verificar e adequar o layout do ambiente para que este atenda melhor os discentes, por exemplo as cadeiras, as que estão no centro ficam em fila (na direção da lousa), as que estão nas laterais ficam de lado (posição paralela a lousa) com isso o aluno tem que rotacionar o pescoço na direção da lousa durante a aula, podendo causa constrangimento na coluna cervical. Em relação o mobiliário, em todas as salas são poucas as cadeiras que possuem assento e encosto acolchoado, sendo este um requisito importante para estes usuários, uma vez que estes são de idade avançada e passam longos períodos de tempo sentados, com isso, a inadequação da cadeira pode causar constrangimentos de fadiga muscular, dores na lombar, dentre outras consequências a coluna vertebral.

Como sugestões de melhorias, propõe-se a análise da melhor disposição das cadeiras no ambiente, a retirada de objetos que não são de uso dos discentes/docentes (armário, mesas e cadeiras em excesso) que ocupam espaço e acumulam sujeira. Além, da substituição das cadeiras existentes por aquelas que possuem assento e encosto acolchoados, sugere-se também a análise das medidas antropométricas destes objetos, uma vez que para as dimensões dos mesmos, utiliza-se a NBR 14006/2003 - Moveis escolares: assentos e mesas para conjunto de alunos de instituições educacionais, que adota os percentis da ISO 5970 e se destina ao público infanto-juvenil. Por isso, torna-se necessário averiguar se estas medidas atendem as dimensões corporais da população idosa.

Os problemas físico-ambientais tratam sobre o nível de iluminância do ambiente, considerando que em uma das salas um dos pontos de luz não funciona, nas demais tem quatro pontos de luz, totalizando oito lâmpadas. Há também a entrada de luz natural pela janela, tornando a iluminação disforme. Além disso, há o ruído provocado pelo ar-condicionado e a oscilação de temperatura do ambiente. Sendo assim, gera-se dificuldades visuais por causa da má iluminação, desgaste auditivo pelos ruídos e o desconforto térmico. Portanto, sugere-se a medição do nível de iluminação do ambiente, para saber se está adequado ao valor estipulado pela NBR 5413/1992, que determina que o nível de iluminância máxima $(500 \mathrm{~lx}$ ) à ambientes de ensino quando a capacidade visual dos observadores está abaixo da média. Quanto a entrada de luz natural, a utilização de uma persiana ou algo similar, pois assim, pode-se controlar a entrada da luz.

Em relação ao ruído, providenciar a manutenção ou troca dos aparelhos de ar-condicionado velhos por novos, para que estes se adequem a NBR 10152 - Níveis de Ruídos para Conforto Acústico, consequentemente, resolve-se a questão da oscilação da temperatura. A NR-17 sugere que para o conforto térmico, o índice de variação efetiva deve estar entre $20^{\circ} \mathrm{C}$ e $23^{\circ} \mathrm{C}$. Porém, para lida e Buarque (2016) nos países tropicais, a zona de conforto pode deslocar-se para a faixa de $25^{\circ} \mathrm{C}$ a $28^{\circ} \mathrm{C}$. Entretanto, em ambientes coletivos, há muitas diferenças individuais e torna-se difícil de satisfazer a 


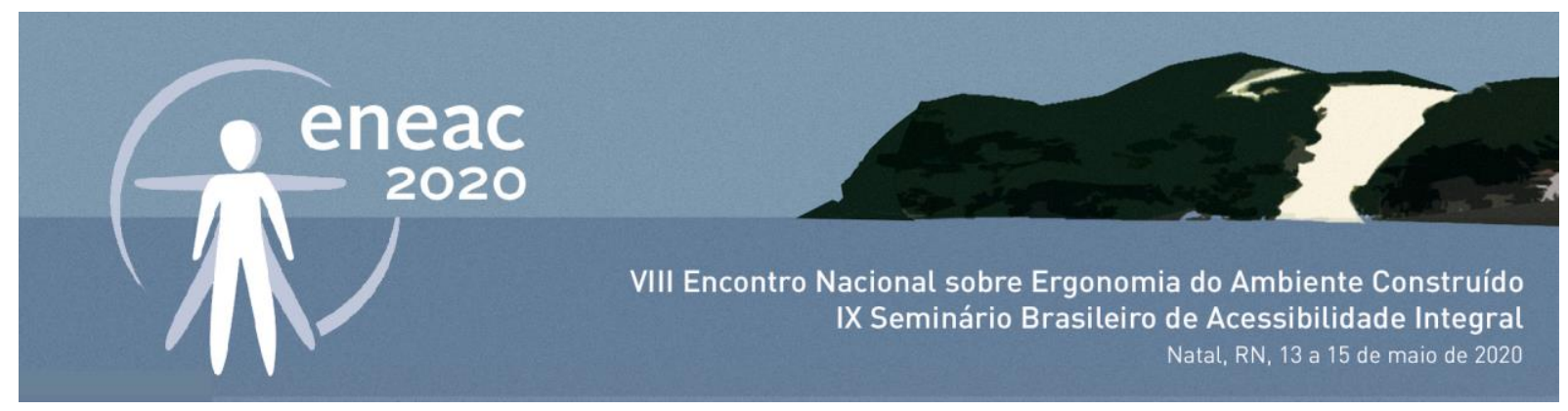

todos. Dessa forma, procura-se regular o ambiente térmico pela média da população (IIDA E BUARQUE, 2016, pg.386).

Contudo, como afirmam Villarouco e Andreto (2008), entende-se que olhar um projeto com os olhos de ergonomista é antever sua utilização, é conjugar condicionantes físicos, cognitivos, antropométricos, psicossociais e culturais, objetivando identificar variáveis não atendidas e/ou necessárias no produto proposto. Portanto, pensar o ambiente educacional para discentes da terceira idade é compreender que este precisa ser pensado/projetado para que atenda às necessidades especificas do seu público. Pois como afirma Moura et al (2018) "geralmente os prédios são antigos e dificilmente são feitas reformas para adequar o espaço a esses novos alunos. As gerações mudam e é interessante que esses espaços como as instituições de ensino e precisamente a sala, sejam convidativos e compatíveis com as novas necessidades dos estudantes". E a ergonomia através dos seus princípios pode proporcionar um ambiente que seja confortável, seguro e eficiente.

\section{CONCLUSÃO}

Considerando o atual processo de envelhecimento populacional, torna-se necessário a conscientização que este público necessita de projetos que dialoguem com suas necessidades. Por isso, ao direcionar o olhar do design para educação da terceira idade, percebe-se que ainda há poucas pesquisas e discussões neste campo de conhecimento. Todavia, a educação tem ressignificado o envelhecimento e proporcionado o sentimento de vivacidade a população idosa.

Nessa perspectiva, tem-se a razão da presente pesquisa, que por meio da Metodologia Ergonômica do Ambiente Construído - MEAC, encontrou-se o método eficaz para avaliar ambiente de ensino da UNITI e identificar os problemas que interferem na eficiência do processo de ensino.

Além desta, na terceira etapa da MEAC, que aborda a percepção do usuário a respeito do objeto estudado, utilizou-se a ferramenta "estrela de valor" proposta por Krucken (2009), para representar graficamente os dados qualitativos para melhor compreensão das informações. Constatando que os valores emocional, simbólico/cultural e social ressaltam a importância da UNITI para os idosos.

Porém, as questões funcionais, que tratam dos aspectos ergonômicos, também são percebidas pelos discentes, mas são atenuadas pelo sentimento de pertencimento que estes têm pela instituição.

Neste sentido, a MEAC aliada a outras ferramentas, mostraram-se meios viáveis para investigação e a aplicação de princípios ergonômicos, pois, com os resultados obtidos pode-se propor a adequação ou construção de ambientes que sejam condizentes com as reais necessidades dos discentes da terceira idade.

\section{AGRADECIMENTOS}

À Coordenação de Aperfeiçoamento de Pessoal de Nível Superior - Brasil (CAPES) - Código de Financiamento 001;

À Fundação de Amparo à Pesquisa e ao Desenvolvimento Científico e Tecnológico do Maranhão FAPEMA. 


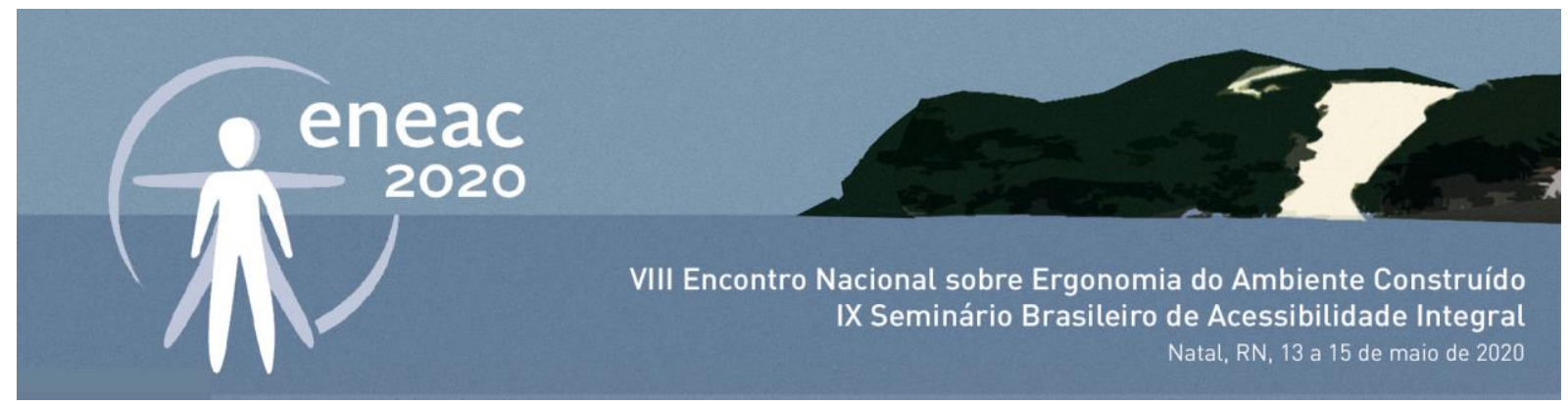

\section{REFERÊNCIAS}

ABNT - Associação Brasileira de Normas Técnicas. NBR 14006 - Móveis escolares: Assentos e mesas para conjunto aluno de instituições educacionais. Rio de Janeiro: ABNT, maio de 2003.

NBR 5413/1992 iluminância de interiores. Rio de Janeiro: ABNT, abril de 1992.

NBR 10152/1997 níveis de ruído para conforto acústico. Rio de Janeiro: ABNT, dezembro de 1987.

Norma Regulamentadora 17 - Ergonomia. Rio de Janeiro: ABNT, junho de 1978.

BARROS, Bruno; CUNHA, Maiana; VILLAROUCO, Vilma; "SALAS DE AULA UNIVERSITÁRIAS: UM ESTUDO SOB A ÓTICA DA ERGONOMIA DO AMBIENTE CONSTRUÍDO", p. 200-211. In: Anais do 15 Ergodesign \& Usihc [Blucher Design Proceedings, vol.2, num.1]. São Paulo: Blucher, 2015.

BRASIL. IBGE. Censo Demográfico, 2010. Disponível em: www.ibge.gov.br. Acesso em: 10 de janeiro de 2020.

CACHIONI, Meire; ORDONEZ, Tiago Nascimento. Universidade da Terceira Idade. In: Tratado de Geriatria e Gerontologia/Elizabete Viana de Freitas...[et al]. - 3.ed. - [reimpressão]. Rio de Janeiro: Guanabara Koogan; 2013.

CARVALHO, José Alberto Magno de; GARCIA, Ricardo Alexandrino. O envelhecimento da população brasileira: um enfoque demográfico. In: Cad. Saúde Pública, Rio de Janeiro, 19(3):725-733, mai-jun, 2003.

FIGUEIREDO, L.; PAOLIELLO, C. Análise Ergonômica do Trabalho: Estudo de caso do Mobiliário Existente nas Escolas Públicas do Vale do Aço. Trabalho de Conclusão de Curso (Graduação em Arquitetura e Urbanismo) - Centro Universitário do Leste de Minas Gerais, Unileste, 2001.

IIDA, Itiro; BUARQUE, Lia. Ergonomia: projeto e produção. 9a reimpressão. São Paulo: Edgard Blucher, 2016.

ISO - International Organization for Standardization. ISO 5970:1979 - Furniture: Chairs and tables for educational institutions -- Functional sizes. 1979.

KRUCKEN, Lia. Design e território: valorização de identidades e produtos locais. São Paulo: Studio Nobel, 2009.

MARCONI, M. de A.; LAKATOS, E. M. Fundamentos de metodologia científica. 7ạ edição, Editora Atlas. São Paulo, 2016.

MOURA, Roberta Clarice Meneses; NEVES, Antonio Alexsandro; BARBOSA, Antonio Carlos Leite; "ANTROPOMETRIA E ERGONOMIA DO MOBILIÁRIO ESCOLAR", p. 1174-1176. In:. São Paulo: Blucher, 2018.

NATALI, Adriana. IES criam programas para o público da terceira idade: tempo de aprender. Disponível em: https://www.revistaensinosuperior.uol.com.br. Acesso em: 11 de janeiro de 2020.

ONU, Organização das Nações Unidas. Plano de Ação Internacional para o Envelhecimento. Tradução de Arlene Santos; revisão de português de Alkmin Cunha; revisão técnica de Jurilza M. B. de Mendonça e Vitória Gois. Brasília: Secretaria Especial de Direitos Humanos, 2003.

ORNSTEIN, S. Avaliação Pós-Ocupação (APO) do ambiente construído. São Paulo: Studio Nobel - Editora da Universidade de São Paulo, 1992.

SBGG, Sociedade Brasileira de Geriatria e Gerontologia. Disponível em: https://www.sbgg.org.br. Acesso em: 13 de janeiro de 2020.

SILVA, Flora Mortiz da. et al. ONDE ESTÃO AS UNTI DAS UNIVERSIDADES PÚBLICAS FEDERAIS DO BRASIL. In: XVII Colóquio Internacional de Gestão Universitária. Novembro, Mar del Plata, Argentina, 2017.

SILVA, J. C. Velhos ou Idosos? A Terceira Idade. 2003

VALENTE, Marcela. América Latina: envelhecimento acelerado, novos desafios. Disponível em: https://www.vermelho.org.br. Acesso em: 11 de janeiro de 2020.

VILLAROUCO, Vilma. An ergonomic look at the work environment. Proceeding from IEA 09: 17th World Congress on Ergonomics. China: Beijing, 2009. 


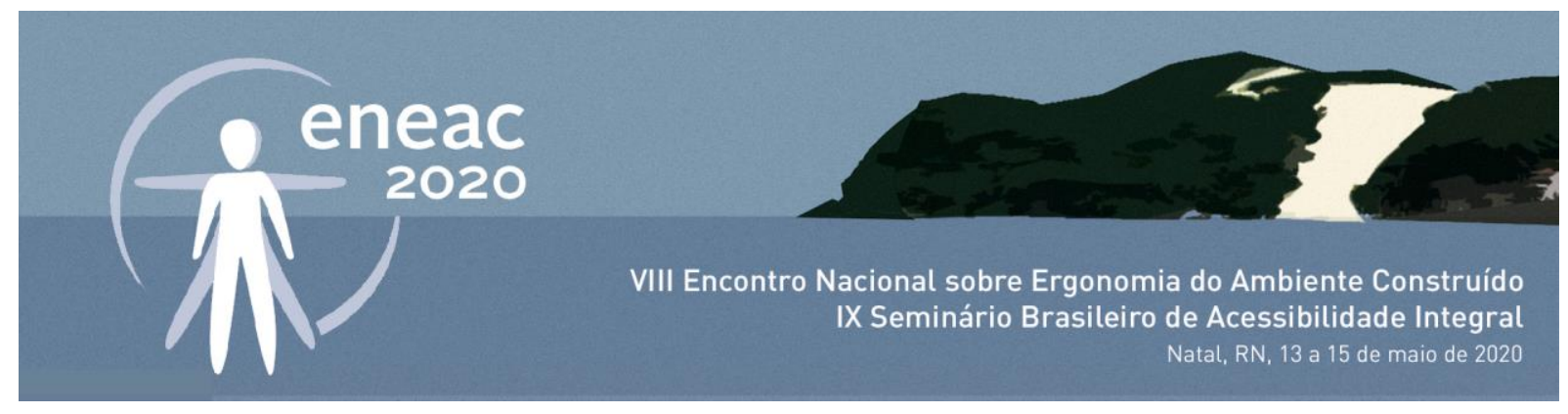

Construindo uma metodologia de avaliação ergonômica do ambiente - AVEA. In: Anais do XV Congresso Brasileiro de Ergonomia - ABERGO- Porto Seguro, 2008.

VILLAROUCO, Vilma; ANDRETO, Luiz F. M. Avaliando desempenho de espaços de trabalho sob o enfoque da ergonomia do ambiente construído. In: Produção, v.18, n.3, set/dez. pg.523-539, 2008. 